\title{
MECANISMOS DE COOPERAÇÃO JURÍDICA INTERNACIONAL E SUA APLICABILIDADE NO BRASIL
}

DOUTORADO EM DIREITO

ORIENTADOR PROFESSOR DOUTOR

JOSÉ CARLOS DE MAGALHÃES

UNIVERSIDADE DE SÃO PAULO

FACULDADE DE DIREITO

SÃO PAULO 



\section{MECANISMOS DE COOPERAÇÃO JURÍDICA INTERNACIONAL E SUA APLICABILIDADE NO BRASIL}

Tese apresentada como exigência parcial para a obtenção do Título de Doutor em Direito ao Programa de Pós-graduação em Direito da Faculdade de Direito da Universidade de São Paulo. Área de concentração: Direito Internacional, sob orientação do Professor Doutor José Carlos de Magalhães.

\section{SÃO PAULO}





\section{CARLOS ALBERTO VILELA SAMPAIO}

Mecanismos de cooperação jurídica internacional e sua aplicabilidade no Brasil.

BANCA EXAMINADORA

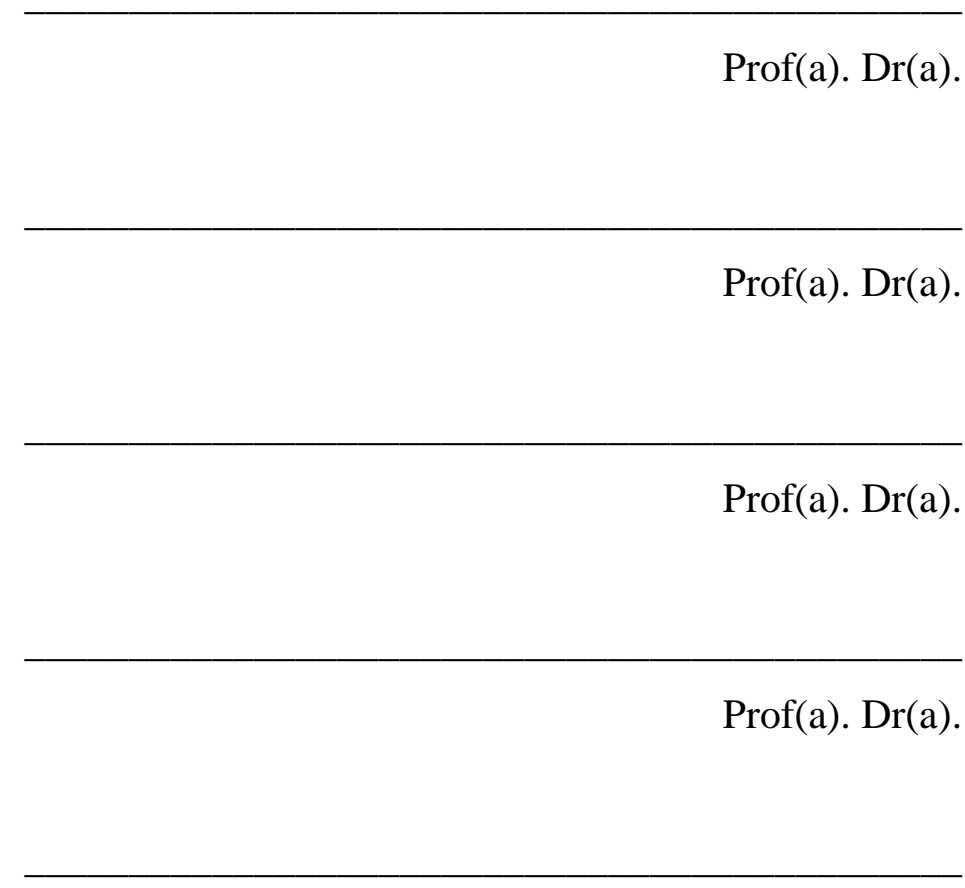

Prof. Dr. José Carlos de Magalhães - Orientador 

À minha Mãe, Suely Vilela, exemplo de dedicação $e$ caráter, pelo amor e apoio irrestrito $e$ incondicional.

Ao meu pai, pela compreensão de minha ausência.

À minha avó Anita, pelo amor e pelas orações que muito me protegeram.

À Amanda, por estar quando o acreditar não mais existia. 



\section{AGRADECIMENTOS}

Ao Professor José Carlos de Magalhães, por acreditar.

Ao Professor João Grandino Rodas, pela amizade, incentivo e apoio de valor inestimável.

Aos professores da Faculdade de Direito da Universidade de São Paulo com os quais tive a oportunidade de conviver e muito aprender nesses últimos anos, em especial ao Prof. Gustavo Ferraz de Campos Monaco, pelo apoio. 



\section{RESUMO}

SAMPAIO, Carlos Alberto Vilela. Mecanismos de cooperação jurídica internacional e sua aplicabilidade no Brasil. 2018. 195 p. Tese (Doutorado em Direito) - Faculdade de Direito da Universidade de São Paulo, São Paulo, 2018.

Cada Estado, no exercício de sua soberania, estabelece seu poder jurisdicional dentro de seu próprio território e nos limites postos pelo direito internacional, de modo que, atualmente, exceto nos casos em que houver norma específica prevista em Tratados disciplinando de maneira diversa, será sempre um tribunal nacional que decidirá o litígio privado de caráter internacional. É de se notar que o aumento da circulação de bens e pessoas entre os Estados incrementa a crescente demanda por efetividade na aplicação das leis internas e torna cada vez mais necessária a existência de mecanismos destinados à cooperação entre eles, com o intuito de possibilitar a aplicação das normas internas dos diversos Estados. De fato, as fronteiras políticas e territoriais limitam o exercício das jurisdições estatais. Assim, caso não haja cooperação entre os Estados, os esforços de um em aplicar sua lei se mostrariam inúteis nas situações em que certos atos devessem ser executados em território de outro. Nesse contexto, insere-se o tema da cooperação jurídica internacional, visto como um conjunto de medidas e mecanismos pelos quais os órgãos competentes dos Estados solicitam e prestam auxílio para realizar, em seu território, atos pré-processuais e processuais que interessam ao Estado estrangeiro. O presente estudo tem como objeto a regulamentação pelo Código de Processo Civil dos mecanismos de cooperação jurídica internacional, quais sejam: a ação de homologação de sentença estrangeira, as cartas rogatórias e o auxílio direto. Tem como tese principal demonstrar o equívoco do legislador ao adotar a natureza jurisdicional como critério determinante de quais decisões estrangeiras devem ser homologadas. O equívoco decorreu da errônea concepção de jurisdição como sendo exclusiva do Estado, o que o levou à redação equivocada de inúmeros artigos. De um lado, manteve a necessidade de homologação para decisões privadas estrangeiras, como o laudo arbitral estrangeiro, e, de outro, dispensou da homologação sentenças estrangeiras de divórcio consensual sem a observância de critérios técnicos. Concluiu-se que o legislador perdeu a oportunidade de adequar a legislação brasileira a critérios técnicos e científicos. Como contribuição, apresenta-se, ao final, uma proposta de redação para os artigos nos quais foram detectados equívocos.

Palavras-chave: Cooperação Jurídica Internacional - Mecanismos - Regulamentação. 



\begin{abstract}
SAMPAIO, Carlos Alberto Vilela. Mechanisms of international legal cooperation and its applicability in Brazil. 2018. 195 p. Thesis (Doctorate in Law) -Law School, University of São Paulo, São Paulo, 2018.

Each State, in the exercise of its sovereignty establishes its jurisdictional power within its own territory and of the limits established by International Law, so that, currently, except in cases where a specific norm is set forth in the Treaties disciplining in a different way, it is a national court that will decide the private litigation of international character. The increase in the circulation of goods and people between States raises the demand for effectiveness of the domestic laws enforcement, what makes even more necessary the establishment of mechanisms for cooperation between those countries, in order to allow the use of the internal rules of the various States. In fact, political and territorial boundaries limit the exercise of state jurisdictions. Thus, in the absence of States cooperation, one's efforts to enforce its own law would be useless in those situations where certain acts should be carried out on the territory of another. In this context, the topic of the international legal cooperation is included, as a set of measures and mechanisms through which the States competent organs request and assist in carrying out, on their territory, the pre-procedural and procedural acts of interest of the foreign State. The aim of this study is the regulation of the mechanisms of international legal cooperation by the Brazilian Civil Procedure Code, which are: the foreign sentence homologation process, letters rogatory (letters of request) and direct aid. Its main objective is to demonstrate the misunderstanding of the legislator when adopting the jurisdictional nature as the determining criterion of which foreign decision must be homologated. The misconception stems from the erroneous conception of jurisdiction as being exclusive to the State, which led to the incorrect writing of various articles. On one side, the legislator maintained the need of foreign private decisions homologation, such as the foreign arbitral award, and, on the other hand, exempted the foreign judgments on consensual divorce of the homologation obligation, without any technical criteria analysis. The conclusion was in the sense that the legislator missed the opportunity to adapt the Brazilian legislation to the technical and scientific criteria. As a contribution, it is presented, at the end, a writing proposal for articles in which the listed misunderstandings were detected.
\end{abstract}

Keywords: International Legal Cooperation - Mechanisms - Regulation. 



\begin{abstract}
ASTRATTO
SAMPAIO, Carlos Alberto Vilela. Meccanismi di cooperazione giuridica internazionale e la sua applicabilità in Brasile. 2018. 195 p. Tesi (Dottorato in Diritto) - Facoltà di Giurisprudenza, Università di San Paolo, San Paolo, 2018.

Ciascuno Stato, nell'esercizio della propria sovranità, stabilisce il proprio potere giurisdizionale all'interno del proprio territorio e dei limiti stabiliti dal diritto internazionale, così che, salvo nei casi in cui una norma specifica è prevista nei trattati, è un tribunale nazionale che deciderà il contenzioso privato di carattere internazionale. L'aumento della circolazione di beni e persone tra gli Stati solleva la richiesta di efficacia dell'applicazione delle leggi nazionali, ciò che rende ancor più necessario l'istituzione di meccanismi di cooperazione tra paesi, al fine di consentire l'uso delle regole interne delle varie Stati. In realtà, i confini politici e territoriali limitano l'esercizio delle giurisdizioni statali. Pertanto, in assenza di cooperazione tra Stati, gli sforzi compiuti per far rispettare la propria legge sarebbero inutili in quelle situazioni in cui determinati atti dovrebbero essere effettuati sul territorio di un altro. In questo contesto, il tema della cooperazione legale internazionale è incluso come una serie di misure e meccanismi attraverso i quali gli Stati competenti organi richiedono e assistono nello svolgimento, sul loro territorio, degli atti pre-procedurali e procedurali di interesse di stranieri Stato. Lo scopo di questo studio è la regolamentazione dei meccanismi di cooperazione legale internazionale da parte del Codice di procedura civile, che sono: il processo di omologazione della sentenza straniera, la rogatoria e il aiuto diretto. Il suo obiettivo principale è dimostrare l'equivoco del legislatore quando si adotta la natura giurisdizionale come criterio determinante per decidire quale decisione straniera deve essere omologata. L'idea sbagliata deriva dall'erronea concezione della giurisdizione come esclusiva per lo Stato, che ha portato alla scrittura scorretta di vari articoli. Da un lato, il legislatore ha mantenuto la necessità dell'omologazione di decisioni private straniere, come il lodo arbitrale straniero, e, d'altro canto, ha esentato le sentenze straniere sul divorzio consensuale dell'obbligo di omologazione, senza alcuna analisi tecnica dei criteri. La conclusione è che il legislatore ha perso l'opportunità di adeguare la legislazione brasiliana ai criteri tecnici e scientifici. Come contributo, alla fine, essere presentata una proposta di scrittura di articoli in cui sono stati rilevati i malintesi elencati.
\end{abstract}

Parole chiave: Cooperazione legale internazionale - Meccanismi - Regolamento. 



\section{SUMÁRIO}

Introdução ............................................................................................................... 19

Capítulo I: Cooperação Jurídica Internacional - Noções Gerais ............................ 25

1.1 Definição .......................................................................................... 25

1.2 O contexto da cooperação internacional ........................................................... 30

1.3 A sistemática adotada pelo Código de Processo Civil ........................................ 34

1.4 Sistema de Delibação .................................................................................. 38

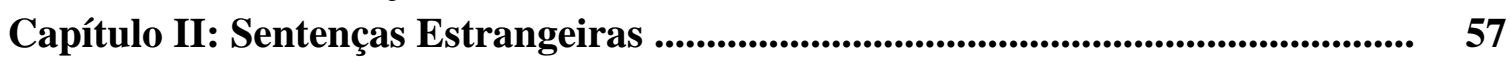

2.1 Escorço histórico ................................................................................... 57

2.2 Objetos da ação de homologação .............................................................. 71

2.2.1 Sentença estrangeira ............................................................................ 72

2.2.2 Decisões estatais estrangeiras ................................................................ 75

2.2.2.1 O critério do art. $961, \S 1^{\circ}$, do CPC: o equívoco ........................................ 79

2.2.3 Laudos arbitrais estrangeiros .................................................................... 87

2.3 Sentenças estrangerias de divórcio consensual ................................................. 115

2.4 Sentenças internacionais .......................................................................... 128

Capítulo III: Cartas Rogatórias ........................................................................... 131

3.1 Definição ....................................................................................... 131

3.2 Objetos das cartas rogatórias ...................................................................... 133

3.2.1 O art. 962, §1º: As cartas rogatórias de conteúdo executório ........................... 137

3.3 Direito Convencional ................................................................................ 154

3.3.1 Convenção Interamericana sobre Cartas Rogatórias ........................................ 154

3.3.2 Protocolo de Las Leñas de Cooperação e Assistência Jurisdicional em

Matéria Civil, Comercial, Trabalhista e Administrativa ............................................ 157

3.3.3 Protocolo de Ouro Preto de Medidas Cautelares ............................................. 162

Capítulo IV: Auxílio Direto ............................................................................................ 167

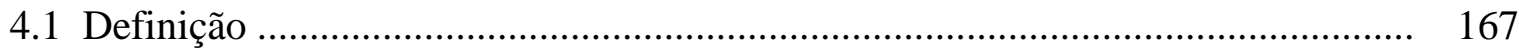

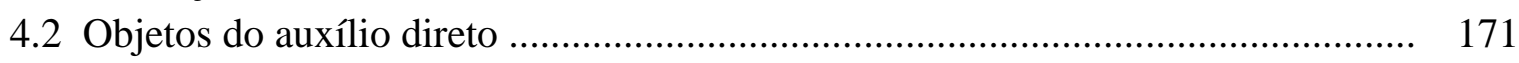

4.3 Direito Convencional ................................................................................. 172

4.3.1 Convenção de Nova Iorque sobre Prestação de Alimentos no Estrangeiro

4.3.2 Convenção da Haia sobre os Aspectos Civis do Sequestro Internacional de Crianças

4.3.3 Convenção contra o Tráfico Ilícito de Entorpecentes e Substâncias

Psicotrópicas

4.3.4 Convenção das Nações Unidas Contra o Crime Organizado Transnacional

4.3.5 Convenção das Nações Unidas contra a Corrupção ......................................... 186

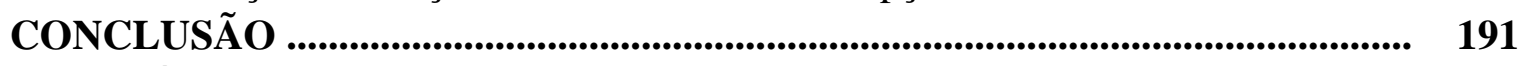

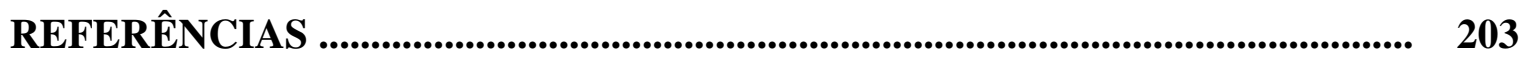





\section{INTRODUÇÃO}

Os Estados, por meio de seu poder soberano, estabelecem poder jurisdicional dentro de seu próprio território e nos limites postos pelo direito internacional, visando que seus tribunais decidam os litígios abarcados pela extensão de sua jurisdição. Ocorre que, diante do processo de globalização, as fronteiras geográficas já não mais representam grande obstáculo à circulação de bens, serviços, mercadorias, capitais e, sobretudo, de informações.

Temas que antes eram estruturados sob uma ótica estritamente nacional passam à escala mundial, modificando por completo a dinâmica das relações econômicas, financeiras e sociais.

Aos Estados, invariavelmente, apresentam-se os desafios de garantir que a regulação das relações, por meio das suas legislações, se compatibilize com o dever que eles, e a sociedade internacional, têm de proteger os direitos humanos independentemente das jurisdições; de assegurar que a internacionalização das relações privadas não se reverta em impunidade ou na inaplicabilidade das leis do foro; e de conferir às relações privadas internacionais o nível de segurança e previsibilidade necessários para que elas sejam sustentáveis a longo prazo.

A efetividade da justiça, dentro deste cenário de intensificação de relações entre nações e seus povos, seja no âmbito comercial, migratório ou informacional, demanda cada vez mais um Estado proativo e colaborativo.

Neste contexto insere-se o presente estudo.

Destacamos, inicialmente, que o presente trabalho se ocupa da cooperação jurídica horizontal, aquela que se estabelece entre os Estados igualmente soberanos, e não da cooperação jurídica vertical, que ocorre entre organizações supranacionais e internacionais, de um lado, e Estados, de outro. 
Tendo em vista a recente regulamentação da cooperação jurídica internacional feita pelo Código de Processo Civil, dedicando-lhe, inclusive, capítulo exclusivo na Parte Geral, nos vimos interessados em estudá-la com o objetivo de extrair conclusões que possam contribuir para o desenvolvimento da cooperação jurídica internacional no Brasil. Portanto, o presente estudo ocupou-se da parte geral e dos mecanismos de cooperação jurídica internacional, a saber: Ação de Homologação de Sentenças Estrangeiras, Cartas Rogatórias e Auxílio Direto.

Delimitado o objeto, cumpre-nos, de imediato, esclarecer a tese principal, razão de ser do presente estudo.

A tese principal reside em demonstrar que o legislador se equivocou ao adotar, no art. 961, $\$ 1^{\circ}$, do Código de Processo Civil, o critério da jurisdicionalidade como determinante de quais decisões estrangeiras devem ser homologadas para, só então, estarem aptas ao seu cumprimento em território nacional. Defendemos, mais precisamente no Capítulo II, que apenas as decisões estatais estrangeiras, aquelas cujo poder jurisdicional do órgão prolator da decisão ou ato estrangeiro tenha sido conferido pelo Estado, devem ser homologadas.

Para tanto, pesquisou-se a respeito da origem da jurisdição, acerca do tratamento conferido à temática pela legislação brasileira desde o Decreto $\mathrm{n}^{\circ} 6.982$, de 1878 , até a Constituição Federal de 1988, bem como a posição da doutrina. Antes disso, no entanto, no Capítulo I, foram traçadas as bases do sistema de delibação, que é o substrato da sistemática dos processos de homologação de decisões estatais estrangeiras, adotadas não só pelo Código de Processo Civil, mas desde as primeiras legislações brasileiras.

Como teses acessórias, por assim dizer, procuramos demonstrar que o legislador perdeu a oportunidade de adequar a regulamentação do laudo arbitral à sua natureza privada, bem como que poderia ter avançado na aproximação da legislação brasileira a um sistema de delibação menos controlador dos efeitos das decisões estatais estrangeiras e, portanto, mais puro. 
A primeira tese acessória decorre das mesmas premissas adotadas na tese principal. Procuramos demonstrar que o equívoco promovido pela Lei de Arbitragem, ao equiparar laudo arbitral à sentença, poderia ter sido corrigido pelo legislador processual civil com a catalogação do laudo arbitral como título executivo extrajudicial e, com a limitação das matérias passíveis de serem arguidas em embargos à execução, o que se justifica pela característica da definitividade que acompanha tanto a sentença quanto o laudo arbitral, eliminando, consequentemente, a indesejada necessidade de homologação do laudo arbitral estrangeiro perante o Superior Tribunal de Justiça.

A segunda tese acessória propõe, com base na distinção existente entre eficácia executiva e eficácia imperativa das sentenças, que o legislador deveria ter dispensado da homologação não só as sentenças estrangerias de divórcio consensual, mas todas as demais decisões estatais estrangeiras declaratórias de estado das pessoas, do mesmo modo que fizera o art. 15, p. único, da antiga Lei de Introdução ao Código Civil, hoje denominada Lei de Introdução às Normas do Direito Brasileiro.

Ao final, além de nossas conclusões, propusemos, como contribuição decorrente das teses que procuramos comprovar, algumas providências legislativas que, a nosso sentir, dariam maior cientificidade e coerência ao sistema de homologação de decisões estatais estrangeiras, caso adotadas.

Naturalmente, não apenas estas questões foram versadas, de modo que o trabalho está estruturado conforme a seguir.

No Capítulo I, buscou-se, incialmente, definir a cooperação jurídica internacional e justificar as razões pelas quais adotamos esta terminologia. Na sequência, foi traçado um panorama da realidade da cooperação jurídica internacional frente à globalização, bem como tentou-se esclarecer as razões pelas quais os Estados devem cooperar. Procurou-se, ainda, elucidar pontos importantes da sistemática adotada pelo Código de Processo Civil acerca da cooperação jurídica internacional. 
No Capítulo II, além das teses acima destacadas, foi feito um esboço histórico do mecanismo cooperacional Ação de Homologação de Sentença Estrangeira, que foi seguido da análise dos objetos da ação de homologação, onde se encontram as teses defendidas neste estudo.

No Capítulo III, tratamos das Cartas Rogatórias que, ao lado da ação de homologação de sentenças estrangeiras, é dos mais tradicionais mecanismos de cooperação jurídica internacional. Inicialmente, tratamos de definir o instituto e tecemos breves comentários sobre seus tipos e sobre as inovações trazidas pelo Código de Processo Civil.

Em seguida, consideramos seus objetos. Neste passo, analisamos a evolução jurisprudencial do mecanismo, sobretudo quanto à possibilidade de serem veiculadas medidas de cunho executório por carta rogatória. Por fim, comentamos as principais convenções referentes ao mecanismo, sendo elas a Convenção Interamericana sobre Cartas Rogatórias; o Protocolo de Las Leñas de Cooperação à Assistência Jurisdicional em Matéria Civil, Comercial, Trabalhista e Administrativa; e o Protocolo de Ouro Preto de Medidas Cautelares.

No Capítulo IV, tratamos do Auxílio Direto. A sua inserção como mecanismo autônomo foi, a nosso sentir, a vedete da regulamentação feita pelo Código de Processo. O mecanismo surgiu, incialmente, como espécie de carta rogatória, prevista no art. $7^{\circ}, \mathrm{p}$. único, da Resolução $n^{\circ} 9$ do Superior Tribunal de Justiça.

O mecanismo que vem ocupar espaço das cartas rogatórias permite levar a cognição do pedido diretamente ao juiz de primeira instância, sendo desnecessário o juízo prévio de delibação no STJ. Revela-se, em razão disso, um mecanismo mais célere e aberto, especialmente no que diz respeito à amplitude das medidas que, por meio dele, podem ser solicitadas e, do rol de autoridades, legitimadas a utilizá-lo.

Neste capítulo, seguindo a linha do que fora feito, quando da análise dos dois outros mecanismos, inicialmente, definimos o instituto e tecemos breves comentários sobre as inovações trazidas pelo Código de Processo Civil. Também foi analisada a evolução da 
jurisprudência a respeito de sua aceitação como mecanismo de cooperação jurídica internacional.

Na sequência, analisamos seus objetos e, por fim, comentamos os principais tratados e convenções, vigentes no Brasil, que previam, antes mesmo da Resolução $n^{\circ} 9$ do STJ, o procedimento do auxílio direto - sendo elas a Convenção de Nova Iorque sobre Prestação de Alimentos no Estrangeiro, a Convenção da Haia sobre os Aspectos Civis do Sequestro Internacional de Crianças, a Convenção contra o Tráfico Ilícito de Entorpecentes e Substâncias Psicotrópicas, a Convenção das Nações Unidas contra o Crime Organizado Transnacional e a Convenção das Nações Unidas contra a Corrupção.

Ao final, trouxemos nossas conclusões e, em decorrência das teses defendidas, uma proposta de ajustamento da redação dos artigos que reputamos, para conter redação diversa.

É de se ressaltar, como se verá, que as teses defendidas no presente estudo representam um desejo de contribuir para o aperfeiçoamento do ordenamento jurídico brasileiro, no que concerne à cooperação jurídica internacional, mas que, naturalmente, demandam reflexões e avaliações de adequação e praticidade.

Por fim, nos cabe uma ressalva ao leitor quanto ao título do presente estudo. Devido ao adiantado dos dias, o título não pôde mais ser alterado em razão das normas da PósGraduação da Faculdade de Direito da Universidade de São Paulo, sendo que o título que melhor representaria o objeto e a intenção da presente pesquisa seria: A regulamentação dos mecanismos de cooperação jurídica internacional feita pelo Código de Processo Civil. 


\section{CONCLUSÃO}

Como visto, em decorrência do processo de globalização, temas que, antes, eram estruturados sob uma ótica estritamente nacional passaram à escala mundial, modificando por completo a dinâmica das relações econômicas, financeiras e sociais.

Consequentemente, os Estados depararam-se diante dos seguintes desafios: garantir que as regulações das relações humanas, por meio de suas legislações, sejam compatíveis com o dever de proteger os direitos humanos, independentemente das jurisdições; assegurar que a internacionalização das relações privadas não se reverta na inaplicabilidade das leis do foro; e conferir às relações privadas internacionais o nível de segurança e previsibilidade necessários para que elas sejam sustentáveis a longo prazo.

A efetividade da justiça, dentro deste cenário, passou, então, a demandar cada vez mais um Estado proativo e colaborativo, a ponto de nos ser lícito afirmar que a ausência de uma efetiva cooperação, entre eles, acarretará a inutilidade dos esforços de um em aplicar sua lei, nas situações em que certos atos devam ser executados em território de outro.

Inserido neste contexto, o presente estudo desenvolveu-se sob a ótica da regulamentação da cooperação jurídica internacional feita pelo Código de Processo Civil, vinda em boa hora. Demonstrou-se que a regulamentação, com a inserção de capítulo destinado exclusivamente à cooperação jurídica internacional, veio a corroborar o entendimento de que a cooperação, longe de representar a relativização da soberania do Estado, apresenta-se como essencial à sua própria manutenção.

A análise da sistemática adotada pelo Código de Processo Civil demonstrou que o legislador teve a consciência da distinção existente entre via de tramitação, mecanismos de cooperação e conteúdo do auxílio prestado, cuja inexorável consequência é que nem sempre um conteúdo estará associado a um mecanismo e, do mesmo modo, as vias eleitas nem sempre serão exclusivas. Destacou-se que esta mesma concepção está presente no Protocolo de Las Leñas, tendo ele influenciado a Resolução nº 9/2005 do Superior Tribunal de Justiça, neste aspecto. 
Especificamente a respeito dos mecanismos de cooperação, a grande vedete da regulamentação foi a previsão legal do auxílio direto como espécie autônoma de mecanismo de cooperação jurídica internacional, que havia, inicialmente, sido concebido como um tipo de carta rogatória prevista no art. $7^{\circ}$, p. único, da Resolução no 9 do STJ.

Isto porque, muito embora a Resolução $\mathrm{n}^{\circ} 9$ previsse no art. $7^{\circ}$, p. único, que os pedidos que tivessem por objeto a prática de atos que não ensejassem juízo de delibação não deveriam seguir o procedimento previsto às cartas rogatórias. Houve, como demonstrado pela análise jurisprudencial feita, enorme resistência tanto do STF quanto do STJ em aceitar a utilização do mecanismo.

A sua inserção dentre os mecanismos de cooperação demonstrou a intenção do legislador de tornar a cooperação mais acessível e efetiva, na medida em que, como demonstrado, as autoridades legitimadas a utilizá-lo não se restringem a ocupantes do poder judiciário e, também, porque passa a ser um mecanismo residual, quando encarado sob o prisma de seus objetos.

Em outras palavras, é destinado a veicular pedidos de realização de medidas que não decorram de decisões estrangeiras que devam ser submetidas ao juízo de delibação, o que revela a amplitude das medidas que, por meio dele, podem ser solicitadas, de modo que passa a se ocupar de inúmeros objetos, antes veiculados por meio das cartas rogatórias.

Quanto às cartas rogatórias demonstrou-se a predileção do legislador para que ela seja utilizada como veículo de pedidos de cumprimento de decisões interlocutórias, na medida em que, com a positivação do auxílio direto, justificativa não mais há e, sob o prisma da utilidade do procedimento, já não havia - faltava apenas o respaldo legal para que o procedimento destinado às cartas rogatórias fosse utilizado para pedidos que não ensejem a prática de juízo de delibação que, como se viu, é a razão de ser do auxílio direito.

Importante conduta do legislador foi a de positivar como objeto possível das cartas rogatórias a decisão interlocutória estrangeira concessiva de urgência (art. 962, §1º, do 
CPC), tema que, como demonstrado pela evolução da jurisprudência, ocupou significativo espaço nas decisões do STF e do STJ, antes e depois da Resolução nº 9/2005.

Viu-se, com tudo isso, que o legislador foi influenciado pela Resolução $n^{\circ} 9$ e pela evolução jurisprudencial, no que concerne à aceitação do auxilio direto e à admissão do conteúdo executório para as cartas rogatórias, vindo com a positivação "lançar uma pá de cal" sobre as dúvidas que, por ventura, ainda possam existir.

É de se registrar, como por vezes destacado no presente estudo, a importância da Emenda Constitucional 45 de 2004 que, ao retirar do Supremo Tribunal Federal e atribuir ao Superior Tribunal de Justiça a competência para conceder exequatur às cartas rogatórias e homologar sentenças estrangeiras, a nosso ver, foi o grande marco de um processo de evolução da cooperação jurídica internacional no Brasil, que culmina, mas não se encerra, na edição do vigente Código de Processo Civil.

Entretanto, não foi só.

Na regulamentação da homologação das decisões estrangeiras residiu o principal motivo do presente estudo, bem como a tese defendida. O propósito foi demonstrar o equívoco cometido pelo legislador ao inserir no art. $961, \S 1^{\circ}$, do CPC o critério da jurisdicionalidade como determinante de quais decisões estrangeiras devem ser submetidas ao juízo de delibação, com vistas a sua posterior execução.

A razão do equívoco foi desconsiderar que a jurisdição - poder de declarar e tornar efetivo o direito - não é originária, e tampouco exclusiva, do Estado. Para tanto, demonstrou-se, com base na redação de todas as legislações brasileiras e também com fundamento doutrinário, que o povo visto como nação é quem detém o poder de declarar e atuar o direito, de forma originária. Delega-o, por meio da Constituição Federal, ao Estado, mas não de forma irrestrita, para que ele atue em seu nome, por meio das funções executiva, legislativa e jurisdicional. 
Demonstrou-se, assim, que o exercício da jurisdição não é exclusivo do Estado e que tampouco todo litigio necessariamente é composto pela intervenção estatal, o que nos levou a concluir que o fato de haver atividade jurisdicional não empresta à decisão o atributo da oficialidade. Logo, vimos que nem toda decisão ou ato que declare um direito e/ou torne-o efetivo detém os mesmos atributos, efeitos e consequências de uma decisão ou ato estatal.

Ao lado disso, comprovou-se que a legislação brasileira, desde a edição do Decreto $n^{\circ}$ 6.982/1878, passando por todas as Constituições até a Constituição Federal de 1988, com a redação que lhe foi dada pela EC 45/2004, sempre conteve a clareza de que o que é passível de homologação são as sentenças estrangeiras, atos de Estado. Demonstrou-se, inclusive, que essa foi a opinião de autores de renome, a exemplo de Serpa Lopes, Hildebrando Accioly, Oscar Tenório, entre outros.

Concluiu-se, portanto, que o fato de ter havido exercício de atividade jurisdicional não é o critério cientificamente correto para determinar o que deve ser homologado, sendo correto o critério da oficialidade das decisões. Segundo este critério, devem ser homologadas apenas as decisões estatais estrangeiras, assim consideradas as decisões ou atos proferidos por órgãos cujo poder jurisdicional tenha sido conferido pelo Estado.

Propusemos, como contribuição decorrente da tese defendida, que o ajustamento poderia ser viabilizado por meio de alteração na redação de alguns artigos do Código de Processo Civil, consubstanciado nas seguintes providências: a exclusão do parágrafo primeiro do artigo 961 e nos artigos 40, 960, 961, 962, 963, 964 e 965, a inserção da expressão estatal (estatais) logo após à expressão decisão (decisões), sempre que o dispositivo legal estiver referindo ao que deve ser homologado.

Ainda na análise dos objetos da ação de homologação de sentença estrangeira, demosntramos que o legislador perdeu a oportunidade de adequar a regulamentação do laudo arbitral a sua natureza privada e, consequentemente, dispensar o laudo arbitral estrangeiro do procedimento de homologação junto ao STJ. 
Carlos Alberto Carmona, um dos membros da Comissão Redatora da Lei de Arbitragem, ao justificar a equiparação entre laudo arbitral e sentença, feita pelo art. 31 da Lei de Arbitragem, esclareceu que fora adotada a tese da jurisdicionalidade da arbitragem. Nada mais equivocado, como demonstado acima.

A doutrina esclareceu, à época, que o legislador buscava conferir prestígio ao laudo arbtiral e, para tanto, buscou limitar as matérias de defesa na execucão do laudo arbitral ao catalogá-lo como título executivo judicial. Afinal, o art. 745 do Código de Processo Civil, vigente à época da entrada em vigor da Lei de Arbitragem, possibilitava que o executado arguisse qualquer matéria lícita de ser considerada em defesa no processo de conhecimento, quando da apresentação de seus embargos à execução de título executivo extrajudicial.

Demosntramos, todavia, que o nobre desiderato poderia ter sido obtido catalogando o laudo como título executivo extrajudicial e limitando as matérias de defesa na execucão das mesmas, passíveis de alegação na impugnação ao cumprimento de sentença, prevista no art. 741 do Código de Processo Civil vigente à época, sem a possibildiade de o executado arguir quaisquer matérias passíveis de serem dedzuidas em defesa no processo de conhecimento. Com relação ao laudo arbitral estrangeiro, a matéria de defesa restaria limitada ao que consta dos incisos dos arts. 38 e 39 da Lei de Arbitragem.

Esclarecemos que o que justifica a limitação das matérias passíveis de serem alegadas em defesa na execucão é a caraterística de definitividade que acompanha tanto a sentença quanto o laudo arbitral, o que respaldaria a conduta legislativa acima proposta e evitaria a utilização equivocada do subterfúgio da jurisdicionalidade.

Propusemos, como contribuição decorrente da tese defendida, que o ajustamento do laudo arbitral a sua natureza privada poderia ser viabilizado por meio de alteração na redação de alguns artigos do Código de Processo Civil, consubstanciado nas seguintes providências: inserir o laudo arbitral e o laudo arbitral estrangeiro no rol dos títulos executivos extrajudiciais previstos no artigo 784, e não nos inicisos VII e VIII do art. 515, 
os quais que prevêem como títulos executivos judiciais, respectivamente, o laudo arbitral e o laudo arbitral estrangeiro homologado pelo Superior Tribunal de Justiça;

V. inserir um parágrafo no artigo 917 especificando as matérias passíveis de arguição em embargos à execução de laudo arbitral nacional às hipóteses previstas no art. 525, $\S 1^{\circ}$, do Código de Processo Civil;

VI. inserir mais um parágrafo no artigo 917 delimitando as matérias passíveis de arguição em embargos à execução de laudo arbitral estrangeiro ao que consta dos incisos dos artigos 38 e 39 da Lei de Arbitragem; e

VII. inserir um artigo nas Disposições Finais e Transitórias do Livro Complementar dando nova redação ao artigo $31^{391}$, e outro determinando que os artigos que contivessem a expressão "sentença arbitral" passariam a vigorar com a expressão "laudo arbitral", e outro revogando os art. 34, 35, 36, 37, 39 e 39, todos da Lei de Arbitragem.

Demonstramos, também, no capítulo II, que legislador poderia ter avançado um pouco mais na tentativa de se aproximar de um sistema de delibação mais puro. Para tanto, deveria ter dispensado da homologação não só as sentenças estrangeiras de divórcio consensual, mas todas as decisões estatais estrangeiras declaratórias de estado das pessoas, tal qual fizera o art. 15, p. único da Lei de Introdução ao Código Civil.

O fundamento para tal conduta legislativa é a distinção que há entre os efeitos declaratórios e constitutivos decorrentes da situação jurídica de coisa julgada (eficácia imperativa da sentença) e os efeitos executórios (eficácia executiva da sentença), sendo que os primeiros, ao contrário dos efeitos executórios, exaurem-se naturalmente, independentemente de qualquer providencia jurisdicional e, portanto, não podem ser dissociados do conceito de sentença.

${ }^{391}$ Art. 31. O laudo arbitral nacional e o estrangeiro constituem títulos executivos extrajudiciais. 
Assim, partindo do pressuposto de que o que se homologa é a sentença estrangeira com toda a eficácia que lhe é inerente, a consequência disto seria que o processo de homologação restaria necessário apenas para a liberação dos efeitos executórios das decisões estatais estrangeiras.

Ainda com relação às sentenças estrangeiras de divórcio, perquirimos a respeito das razões que teriam levado o legislador a apenas excluir da regra da homologação as sentenças estrangeiras de divórcio consensual, não dispensando o mesmo tratamento às sentenças estrangeiras de divórcio litigioso. Concluímos que o legislador, provavelmente, adotou uma medida de administração da justiça, na medida em que a maioria das decisões estrangeiras submetidas à homologação junto ao STJ eram de divórcio e, muitas delas, sequer eram contestadas.

Defendemos que a conduta do legislador, embora possa ser justificada como uma medida política de administração da justiça, é desprovida de técnica, na medida em que, conforme demonstrado, os efeitos das decisões estatais estrangeiras de divórcio exauremse naturalmente, pelo que, quando pouco, todas as sentenças estrangeiras de divórcio, seja decorrente de um consenso ou não, deveriam receber este tratamento.

Por fim, da análise da redação do art. $961, \S 5^{\circ}$, do CPC, que no caput refere-se às decisões estrangeiras (gênero) e, no $\S 5^{\circ}$, às sentenças (espécie de gênero decisões), concluímos que o legislador, intencionalmente e sem razão técnica, não confere o mesmo tratamento às decisões ou atos estatais estrangeiros não proferidos por órgãos do poder judiciário, mas cujo poder jurisdicional do órgão prolator tenha sido conferido pelo Estado, como, por exemplo, os divórcios consensuais registrados perante os Registros de Família do Japão.

Apresentamos, como consequência da tese defendida, a nossa proposta de redação para os seguintes artigos do Código de Processo Civil:

Art. 40. A cooperaçao jurídica internacional para a execução de decisão estatal estrangeira 
dar-se-á por meio de carta rogatória ou de ação de homologação de sentença estrangeira, de acordo com o capítulo VI.

Art. 784. São títulos executivos extrajudiciais:

I - a letra de câmbio, a nota promissória, a duplicata, a debênture e o cheque;

$[\ldots]$

XII - laudo arbitral nacional;

XIII - laudo arbitral estrangeiro;

XIV - todos os demais títulos aos quais, por disposição expressa, a lei atribuir força executiva.

Art. 917. Nos embargos à execução, o executado poderá alegar:

I - inexequibilidade do título ou inexigibilidade da obrigação;

II - penhora incorreta ou avaliação errônea;

III - excesso de execução ou cumulação indevida de execuções;

IV - retenção por benfeitorias necessárias ou úteis, nos casos de execução para entrega de coisa certa;

V - incompetência absoluta ou relativa do juízo da execução;

VI - qualquer matéria em que lhe seria lícito deduzir como defesa em processo de conhecimento.

$\S 1^{\underline{o}}$ A incorreção da penhora ou da avaliação poderá ser impugnada por simples petição, no prazo de 15 (quinze) dias, contado da ciência do ato.

$[\ldots]$

$\$ \boldsymbol{8}^{\boldsymbol{o}} \mathrm{Na}$ execução de laudo arbitral nacional o executado poderá alegar:

I - falta ou nulidade da citação se o procedimento arbitral correu à revelia;

II - ilegitimidade de parte;

III - inexequibilidade do título ou inexigibilidade da obrigação;

IV - penhora incorreta ou avaliação errônea;

V - excesso de execução ou cumulação indevida de execuções;

VI - incompetência absoluta ou relativa do juízo da execução;

VII - qualquer causa modificativa ou extintiva da obrigação, como pagamento, novação, compensação, transação ou prescrição, desde que supervenientes ao laudo. 
$\boldsymbol{\$}^{\boldsymbol{0}} \mathrm{Na}$ execução de laudo arbitral estrangeiro, o executado somente poderá alegar que:

I - as partes na convenção de arbitragem eram incapazes;

II - a convenção de arbitragem não era válida segundo a lei à qual as partes a submeteram, ou, na falta de indicação, em virtude da lei do país onde o laudo arbitral foi proferido;

III - não foi notificado da designação do árbitro ou do procedimento de arbitragem, ou tenha sido violado o princípio do contraditório, impossibilitando a ampla defesa;

IV - o laudo arbitral foi proferido fora dos limites da convenção de arbitragem, e não foi possível separar a parte excedente daquela submetida à arbitragem;

V - a instituição da arbitragem não está de acordo com o compromisso arbitral ou cláusula compromissória;

VI - o laudo arbitral não se tenha, ainda, tornado obrigatório para as partes, tenha sido anulado ou, ainda, tenha sido suspenso por órgão judicial do país onde foi prolatado.

VII - segundo a lei brasileira, o objeto do litígio não é suscetível de ser resolvido por arbitragem;

VIII - a decisão ofende a ordem pública nacional.

$\S 10^{\circ}$ Para efeitos do parágrafo anterior, o juiz ao qual for submetida a execução do laudo denegará o prosseguimento da execução, ainda que não tenha sido alegado em embargos ou mesmo se antes de apresentado se verificar que a decisão ofende a ordem pública nacional ou que o objeto do litígio não é suscetível de ser resolvido por arbitragem, segundo a lei brasileira.

$\S 11^{\circ}$ Para efeito dos parágrafos $9^{\circ}$ e $10^{\circ}$, não será considerada ofensa à ordem pública nacional a efetivação da citação da parte residente ou domiciliada no Brasil, nos moldes da convenção de arbitragem ou da lei processual do país onde se realizou a arbitragem, admitindo-se, inclusive, a citação postal com prova inequívoca de recebimento, desde que assegure à parte brasileira tempo hábil para o exercício do direito de defesa.

Art. 960. A decisão estatal estrangeira somente será executada no Brasil após sua homologação ou após concedido o exequatur à carta rogatória que a transmita, salvo diposição especial em sentido diverso do previsto em lei ou tratado.

$\S 1^{\circ}$ A decisão interlocutória estatal estrangeira poderá ser excutada no Brasil por meio de carta rogatória. 
$\S 2^{\circ}$ Haverá homologação de decisão estrangeira para fins de excecução fiscal quando prevista em tratado ou em promessa de reciprocidade apresentada à autoridade brasileira.

Art. 961. As decisoes estatais estrangeiras declaratórias de estado produzem efeitos no Brasil, independentemente de homologaçao pelo Superior Tribunal de Justiça. Nestes casos, competirá a qualquer juiz examinar a validade da decisão, bem como se ela não ofende a ordem pública, em caráter principal ou incidental, quando essa questão for suscitada em processo de sua competência.

Art. 962. A homologação de decisão estatal estrangeira será requerida por ação de homologação de sentença estrangeira, salvo diposição especial em sentido diverso prevista em tratado.

$\S 1^{\circ}$ A homologação obedecerá ao que dispuser os tratados em vigor no Brasil e o Regimento Interno do Superior Tribunal de Justiça.

$\S 2^{\circ}$ A decisão estatal estrangeira poderá ser homologada parcialmente.

$\S 3^{\circ}$ A autoridade judiciária brasielira poderá deferir pedidos de urgência e realizar atos de execução provisória no processo de homologação de sentença estrangeira.

Art. 963. É passível de execução a decisão estatal estrangeira concessiva de medida de urgência.

$\S 1^{\circ} \mathrm{A}$ execução no Brasil de decisão interlocutória estatal estrangeira concessiva de medida de urgência dar-se-á por carta rogatória.

$\S 2^{\underline{o}}$ A medida de urgência concedida sem audiência do réu poderá ser executada, desde que garantido o contraditório em momento posterior.

$\S 3^{\text {o }} \mathrm{O}$ juízo sobre a urgência da medida compete exclusivamente à autoridade jurisdicional prolatora da decisão estrangeira.

§ 4º Quando dispensada a homologação para que a decisão estatal estrangeira produza efeitos no Brasil, a decisão concessiva de medida de urgência dependerá, para produzir efeitos, de ter sua validade expressamente reconhecida pelo juiz competente para dar-lhe cumprimento, dispensada a homologação pelo Superior Tribunal de Justiça.

Art. 964. Constituem requisitos indispensáveis à homologação da decisão:

I - ser proferida por autoridade competente; 
II - ser precedida de citação regular, ainda que verificada a revelia;

III - ser eficaz no país em que foi proferida;

IV - não ofender a coisa julgada brasileira;

V - estar acompanhada de tradução oficial, salvo disposição que a dispense prevista em tratado;

VI - não conter manifesta ofensa à ordem pública.

Parágrafo único. Para a concessão do exequatur às cartas rogatórias, observar-se-ão os pressupostos previstos no caput deste artigo e no art. $963, \S 2^{2}$.

Art. 965. Não será homologada a decisão estatal estrangeira na hipótese de competência exclusiva da autoridade judiciária brasileira.

Parágrafo único. $\mathrm{O}$ dispositivo também se aplica à concessão do exequatur à carta rogatória.

Art. 965 -A. O cumprimento de decisão estatal estrangeira far-se-á perante o juízo federal competente, a requerimento da parte, conforme as normas estabelecidas para o cumprimento de decisão nacional.

Parágrafo único. O pedido de execução deverá ser instruído com cópia autenticada da decisão homologatória ou do exequatur, conforme o caso.

Art. 1.061. O $\S 3^{\circ}$ do art. 33 da Lei $\mathrm{n}^{\circ}$ 9.307, de 23 de setembro de 1996 (Lei de Arbitragem), passa a vigorar com a seguinte redação:

$[\ldots]$.

Art. 1061 - A. O art. 31 da Lei no 9.307, de 23 de setembro de 1996 (Lei de Arbitragem), passa a vigorar com a seguinte redação:

“Art. 31. Os laudos arbitrais nacional e estrangeiro constituem títulos executivos extrajudiciais."

Art. 1061 - B. Revogam-se os art. 34, 35, 36, 37, 39 e 39 da Lei n $^{\circ} 9.307$, de 23 de setembro de 1996 (Lei de Arbitragem). 



\section{REFERÊNCIAS ${ }^{392}$}

ABADE, Denise Neves. Direitos Fundamentais na Cooperação Jurídica Internacional. São Paulo: Saraiva, 2013

ACCIOLY, Hildebrando. Convenção sobre Arbitragem Comercial Internacional. Revista de Arbitragem e Mediação, São Paulo, Revista dos Tribunais, ano 5, n. 18, p. 245, set. 2008.

Convenção sobre reconhecimento e execução de sentenças arbitrais estrangeiras. Revista de Arbitragem e Mediação, São Paulo, Revista dos Tribunais, ano 5, n. 18, p. 246-248, set. 2008.

. Projeto de Convenção sobre a execução de sentenças arbitrais internacionais. Revista de Arbitragem e Mediação, São Paulo, Revista dos Tribunais, ano 5, n. 18, p. 239-241, set. 2008.

. Projeto de Convenção sobre a execução das sentenças arbitrais internacionais. Revista de Arbitragem e Mediação, São Paulo, Revista dos Tribunais, ano 5, n. 18, p. 242-245, set. 2008.

ARANGUENA FANEGO, Coral et al. Cooperación judicial penal em la Unión europea: la orden europea de detención y entrega. Valladolid: Lex Nova, 2005; AMBOS, Kai, MALARINO, Ezequiel e ELSNER, Gisela et al. (eds.). Cooperación y asistencia judicial con la corte penal internacional: contribuciones de América Latina, Alemania, España e Itália. Bogotá: Temis, 2008.

ARAUJO, Nadia de. A Convenção de Nova York sobre o reconhecimento e execução de laudos arbitrais estrangeiros: análise das razões contrárias a sua adoção nos anos 50 do século XX. Revista de Arbitragem e Mediação, São Paulo, Revista dos Tribunais, ano 5, n. 18, p. 42-49, set. 2008.

. Direito internacional privado: teoria e prática brasileira. 5. ed. atual. e ampl. Rio de Janeiro: Renovar, 2011.

ARAUJO, Nadia de (Coord.). Cooperação jurídica internacional no Superior Tribunal de Justiça: comentários à Resolução n. 9/2005. Rio de Janeiro: Renovar, 2010.

ASSIS, Carlos Augusto de; TANAKA, Aurea Christine. Homologação de sentença estrangeira meramente declaratória do estado das pessoas: a propósito do art. 15, par. único, da LICC. Revista de Processo. São Paulo, v. 28, n. 111, p. 81-101, jul./set. 2003.

BARBI, Celso Agrícola. Comentários ao Codigo de Processo Civil: Lei n 5.869, de 11 de janeiro de 1973. Rio de Janeiro: Forense, 1975. v. 1, t. 2.

BARROSO, Luís Roberto; TIBURCIO, Carmen. Homologação de sentença estrangeira: vedação à expropriação de marcas. Revista da ABPI, Rio de Janeiro, n.80, p. 3-20, jan./fev. 2006.

BASSO, Maristela. Curso de direito internacional privado. 2. ed. rev. e atual. conforme a Lei n. 12.376/2010. São Paulo: Atlas, 2011.

BAPTISTA, Luiz Olavo. A vida dos contratos internacionais. Tese (Concurso de Professor Titular de Direito do Comércio Internacional) - Faculdade de Direito da Universidade de São Paulo, São Paulo, 1992.

\footnotetext{
${ }^{392}$ De acordo com a Associação Brasileira de Normas Técnicas. NBR 6023 (2002).
} 
BOUCAULT, Carlos Eduardo de Abreu. A competência jurisdicional do Superior Tribunal de Justiça em matéria de homologação de sentença estrangeira. Revista de Estudos Jurídicos UNESP, Franca, SP, v. 11, n.15, p. 23-30, 2006.

Homologação de sentença estrangeira e seus efeitos perante o STF. São Paulo: Juarez de Oliveira, 1999.

CÂMARA, Alexandre Freitas. Arbitragem: Lei n. 9.307/96. 4. ed. rev., ampl. e atual. Rio de Janeiro: Lumen Juris, 2005.

CARMONA, Carlos Alberto. Arbitragem e processo: um comentário à Lei no 9.307/96. 2. ed. rev. atual. e ampl. São Paulo: Atlas, 2004.

CASELLA, Paulo Borba. Autonomia da vontade, arbitragem comercial internacional e o direito brasileiro. In: TIBURCIO, Carmen; BARROSO, Luís Roberto (Orgs.). Direito internacional contemporâneo: estudos em homenagem ao professor Jacob Dolinger. Rio de Janeiro: Renovar, 2006. p. 737-749.

CASELLA, Paulo Borba e SANCHEZ, Rodrigo Elian (Orgs.) Cooperação Judiciária Internacional. Rio de Janeiro: Renovar, 2002.

CASTRO, Amílcar de. Das execuções de sentenças estrangeiras no Brasil. Belo Horizonte: Imprensa Oficial de Minas Gerais, 1939.

Direito internacional privado. 5. ed., 5. tiragem, atual. pelo prof. Osiris Rocha. Rio de Janeiro: Forense, 2000.

CERVINI, Raúl e TAVARES, Juarez. Princípios de Cooperação Judicial Penal Internacional no Protocolo do Mercosul. São Paulo: Revista dos Tribunais, 2000, p. 51.

CINTRA, Antonio Carlos de Araújo; DINAMARCO, Cândido Rangel; GRINOVER, Ada Pellegrini. Teoria geral do processo. 17. ed. São Paulo: Malheiros, 2001.

CORREIA, António de Arruda Ferrer. Lições de direito internacional privado. Com a colaboração de Luís Xavier. Coimbra: Almedina, 2000. v. 1.

COUTURE, Eduardo. Fundamentos del derecho procesal civil. 3. ed. Buenos Aires: Roque Depalma, 1958.

CRETELLA NETO, José. Curso de arbitragem: arbitragem comercial, arbitragem internacional, lei brasileira de arbitragem, direito privado brasileiro aplicável à arbitragem, instituições internacionais de arbitragem, convenções internacionais sobre arbitragem. 2. ed. Campinas, SP: Milennium, 2009.

CUERDA RIEZU, Antonio. 'De la extradición a la 'euro ordem' de detención y entrega - con un análisis de la doctrina del Tribunal Constitucional español". Madrid: Centro de Estudios Constitucionales, 2003

DINAMARCO. Cândido Rangel. Direito processual civil. São Paulo: José Bushatsky, 1975.

DOLINGER, Jacob. Direito civil internacional: a família no direito internacional privado: casamento e divórcio no direito internacional privado. Rio de Janeiro: Renovar, 1997. v. 1, t. 1. 
Direito internacional privado: parte geral. 9. ed. atual. Rio de Janeiro: Renovar, 2008.

DOLINGER, Jacob; TIBURCIO, Carmen. Direito internacional privado (parte especial): arbitragem comercial internacional. Com a colaboração de Suzana Medeiros. Rio de Janeiro: Renovar, 2003.

DOLINGER, Jacob; TIBURCIO, Carmen. Direito Internacional Privado. Parte Geral e Processo Internacional. Rio de Janeiro: Forense, 2016,

DOLINGER, Jacob; TIBURCIO, Carmen. The forum law rule in international litigation - which procedural law governs proceedings to be performed in foreign jurisdictions: lex foi or lex diligenitae? Texas International Law Journal, v. 33, p. 425-462

ESPÍNOLA, Eduardo; ESPÍNOLA FILHO, Eduardo. A Lei de Introdução ao Código Civil Brasileiro. Rio de Janeiro: Renovar, $3^{a}$ ed., atualizada por Silva Pacheco, Vol. 2 (art. $7^{\circ}$ a $9^{\circ}$ ), 1999.

FONSECA, José Roberto da Fonseca. Natureza e eficácia da sentença internacional. In: MERCADANTE, Araminta de Azevedo; MAGALHÃES, José Carlos de (Coords.). Solução e prevenção de litígios internacionais. Porto Alegre: Livraria do Advogado: 1999. v. 2, p. 83-100.

FUX, Luiz. Homologação de sentença estrangeira. In: TIBURCIO, Carmen; BARROSO, Luis Roberto (Orgs.). Direito internacional contemporâneo: estudos em homenagem ao professor Jacob Dolinger. Rio de Janeiro: Renovar, 2006. p. 643-649.

GRECO FILHO, Vicente. Homologação de sentença estrangeira. São Paulo: Saraiva, 1978.

HUCK, Hermes Marcelo. Sentença estrangeira e lex mercatoria: horizontes e fronteiras do comércio internacional. São Paulo: Saraiva, 1994.

JO, Hee Moon. Moderno direito internacional privado. São Paulo: Ltr, 2001.

KLEEBANK, Susan. Cooperação Judiciária por via Diplomática - avaliação e propostas de atualização do quadro normativo. Brasília: Instituto Rio Branco/Fundação Alexandre Gusmão, 2004.

LEMES, Selma M. Ferreira. A homologação de sentença arbitral estrangeira e a citação da parte brasileira. Resultado: Revista de Mediação e Arbitragem Empresarial, Brasília, ano 3, n. 20, ago./out. 2006. 2003, p. E-4.

O reconhecimento da sentença arbitral estrangeira no Brasil. Valor Econômico, 08 ago.

LIEBMAN, Enrico Tullio. Os limites da jurisdição brasileira. In: Estudos sobre o processo civil brasileiro. São Paulo: Saraiva, 1947. p. 18-26.

LOULA, Maria Rosa Guimarães. A extraterritorialidade das sentenças no Protocolo de Las Leñas sobre cooperação e assistência jurisdicional em matéria civil, comercial, trabalhista e administrativa. In: TIBURCIO, Carmen; BARROSO, Luís Roberto (Orgs.). Direito internacional contemporâneo: estudos em homenagem ao professor Jacob Dolinger. Rio de Janeiro: Renovar, 2006. p. 651-678. 
LOULA, Pedro. Breves reflexões sobre a repercussão da Reforma do Judiciário (Emenda Constitucional $n^{\circ}$ 45/04) no direito internacional brasileiro. In: TIBURCIO, Carmen; BARROSO, Luís Roberto (Orgs.). Direito internacional contemporâneo: estudos em homenagem ao professor Jacob Dolinger. Rio de Janeiro: Renovar, 2006. p. 777-796.

MAGALHÃES, José Carlos de. A cláusula arbitral nos contratos internacionais. Revista de Direito Mercantil Industrial, Econômico e Financeiro, São Paulo, v. 43, p. 29-36, 1981.

Competência internacional do juiz brasileiro e denegação de justiça. Revista dos Tribunais, São Paulo, ano 77, n. 630, p. 52-55, abr. 1988.

Perspectivas da arbitragem comercial no Brasil. Revista de Direito Mercantil, Industrial, Econômico e Financeiro, Nova Série, São Paulo, Malheiros, v. 27, n. 69, p. 24-30, jan./mar. 1988.

Reconhecimento e execução de laudos arbitrais estrangeiros. Revista dos Tribunais, São Paulo, ano 86, v. 740, p. 116-127, jun. 1997.

O Supremo Tribunal Federal e o direito internacional: uma análise crítica. Porto Alegre: Livraria do Advogado, 2000.

A tardia ratificação da Convenção de Nova Iorque sobre a arbitragem: um retrocesso desnecessário e inconveniente. Revista de Arbitragem e Mediação, São Paulo, Revista dos Tribunais, ano 5, n. 18, p. 24-41, set. 2008.

MAGALHÃES, José Carlos de; BAPTISTA, Luiz Olavo. Arbitragem comercial. Rio de Janeiro: Freitas Bastos, 1986.

MARTINS, Pedro A. Batista. Observações sobre o texto do Acordo sobre Arbitragem Comercial Internacional do MERCOSUL. In: TIBURCIO, Carmen; BARROSO, Luís Roberto (Orgs.). Direito internacional contemporâneo: estudos em homenagem ao professor Jacob Dolinger. Rio de Janeiro: Renovar, 2006. p. 751-776.

MARTINS, Pedro A. Batista; LEMES, Selma M.; CARMONA, Carlos Alberto. Aspectos fundamentais da Lei de Arbitragem. Rio de Janeiro: Forense, 1999.

MESQUITA, José Ignácio Botelho de. Da competência internacional e dos princípios que a informam. Revista de Processo, São Paulo, v. 13, n. 50, p. 51-71, abr./jun. 1988.

Sentença estrangeira, eficácia e força probante: divorcio no estrangeiro: ausência de homologação, condição do cônjuge divorciado e estudo. Revista de Processo, São Paulo, v. 11, n. 44, p. 223-233, out./dez. 1986.

MIAJA DE LA MUELA, Adolfo. Derecho internacional privado. 6. ed. Madrid: Atlas, 1972.

MONACO, Gustavo Ferraz de. Guarda Internacional de Crianças. São Paulo: Quartier Latin, 2012.

MOREIRA, José Carlos Barbosa. Comentários ao Código de Processo Civil: Lei n ${ }^{\circ} 5.869$, de 11 de janeiro de 1973. 15. ed. rev. e atual. Rio de Janeiro: Forense, 2010. v. 5 (arts. 476 a 565).

. A Emenda Constitucional 45/2004 e o processo. Revista de Processo, São Paulo, v. 30, n. 130, p. 235-48, dez. 2005. 
Notas sobre o reconhecimento e execução de sentenças estrangeiras. In: TIBURCIO, Carmen; BARROSO, Luís Roberto (Orgs.). Direito internacional contemporâneo: estudos em homenagem ao professor Jacob Dolinger. Rio de Janeiro: Renovar, 2006. p. 549-558.

. Problemas relativos a litígios internacionais. Revista de Processo, São Paulo, v. 17, n. 65, p. 144-161, jan./mar. 1992.

NEVES, Celso. Coisa julgada civil. São Paulo: Revista dos Tribunais, 1971.

PAYNE, Thomas. The Rights of Men. Collector's Edition. Nowark, Conn.: The Eastern Press, 1979.

PEREIRA, Marcela Harumi Takahashi. A sentença estrangeira sem fundamentação pode ser homologada? Revista de Informação Legislativa, Brasília, v. 43, n. 169, p. 203-231, jan./mar. 2005.

PONTES DE MIRANDA, Francisco Cavalcanti. Comentários ao Código de Processo Civil. Rio de Janeiro: Forense, 1974. v. 6

Tratado de direito privado. Rio de Janeiro: Borsoi, 1971. v. 26.

RAMOS, André de Carvalho. O Reconhecimento da sentença arbitral estrangeira e a cooperação jurisdicional no MERCOSUL. In: CASELLA, Paulo Borba (Coord.). Arbitragem: lei brasileira e praxe internacional. 2. ed. São Paulo: LTr, 1999.

RODAS, João Grandino; MONACO, Gustavo Ferraz de. Conferência da Haia de Direito Internacional Privado: A Participação do Brasil. Brasília: Fundação Alexandre Gusmão, 2007.

SALDANHA, Jania Maria Lopes. Cooperação Jurisdicional, Reenvio Prejudicial e Perspectiva para sua adoção no Mercosul. Porto Alegre: Livraria do Advogado, 2001.

SANTOS, Moacyr Amaral. Primeiras linhas de direito processual civil. 22. ed. rev. atual. por Aricê Moacyr Amaral dos Santos. São Paulo: Saraiva, 2002. v. 1.

SERPA LOPES, Miguel Maria de. Comentários às Leis de Introdução ao Código Civil. 2. ed. rev. e aum. Rio de Janeiro: Freitas Bastos, 1959. v. 1 e 3.

SILVA, De Plácido E. Vocabulário Jurídico. Rio de Janeiro: Forense, 16ª ed., 2005.

SILVA, Ricardo Perlingeiro Mendes da. Auxílio direto, carta rogatória e homologação de sentença estrangeira. Revista de Processo, São Paulo, v. 30, n. 128, p. 287-292, out. 2005.

SILVA, Ricardo Perlingeiro Mendes da. "Cooperação Jurídica Internacional e Auxílio Direto" in BARROSO, Luís Roberto e TIBURCIO, Carmen (orgs.). O Direito Internacional Contemporâneo. Estudos em homenagem ao Professor Jacob Dolinger. Rio de Janeiro: Renovar, 2006, p. 797-809.

SOARES, Guido Fernando da Silva. As arbitragens comerciais internacionais no Brasil: vicissitudes. Revista de dos Tribunais, São Paulo, ano 78, v. 641, p. 29-57, mar. 1989. RT 641/29.

. O Supremo Tribunal Federal e as arbitragens comerciais internacionais: "de lege ferenda". $\overline{\text { Revista }}$ de dos Tribunais, São Paulo, ano 78, n. 642, p. 38-71, abr. 1989. 
SOUZA, José Ferreira Marnoco e. Execução extraterritorial das sentenças civeis e commerciaes. Coimbra: F. França Amado, 1898.

STRENGER, Irineu. Curso de direito internacional privado. Rio de Janeiro: Forense, 1978.

STRENGER, Irineu. Direito Processual Internacional. São Paulo: LTr, 2003.

TANAKA, Aurea Christine. O Divórcio dos Brasileiros no Japão. O Direito Internacional Privado e os princípios constitucionais. São Paulo: Kaleidos-Primus, 2005.

TELLECHEA BERGMAN, Eduardo. "La cooperación jurisdiccional internacional en el ámbito del Mercosur, con especial referencia al derecho uruguayo". Revista da AJUFERGS, Porto Alegre, $\mathrm{n}$. 3, p 9-55, 2007.

TENÓRIO, Oscar Accioly. Lei de Introdução ao Código Civil Brasileiro: Decreto-Lei n. 4657, de 4 de setembro de 1942. 2. ed. aum. Rio de Janeiro: Borsoi, 1955.

Direito internacional privado. 7. ed. Rio de Janeiro: Freitas Bastos, 1963. v. 2.

THEODORO JUNIOR, Humberto. Homologação de sentença estrangeira. Revista do Advogado, São Paulo, v. 26, n. 88, p. 75-87, nov. 2006.

TIBURCIO, Carmen. As inovações da EC 45/2004 em matéria de homologação de sentenças estrangeiras. In: . Temas de direito internacional. Rio de Janeiro: Renovar, 2006.

As inovações da EC 45/2004 em matéria de homologação de sentenças estrangeiras. Revista de Processo, São Paulo, v. 31, n. 132, p. 123-139, fev. 2006.

TORNAGHI, Hélio. Comentários ao Código de Processo Civil. São Paulo: Revista dos Tribunais, 1974. v. 1.

VALLADÃO, Haroldo. Direito internacional privado: em base histórica e comparativa, positiva e doutrinária, especialmente dos estados americanos: introdução e parte geral. 3. ed. rev. e atual. Rio de Janeiro: Freitas Bastos, 1971. v. 1.

Direito internacional privado. Rio de Janeiro: Freitas Bastos, 1978. v. 3.

VIDAL FERNÁNDEZ, Begoña. "De la 'asistencia' judicial penal en Europa a un 'espacio comum de justicia europeo" in ARANGUENA FANEGO, Coral (coord.). Cooperación judicial penal em la Unión europea: la orden europea de detención y entrega. Valladolid: Lex Nova, 2005, p. 19-73, 26

VIGORITI, Vincenzo. Homologação e execução de sentenças e laudos arbitrais estrangeiros na Itália. Revista de Processo, Sao Paulo, v. 13, n. 50, p. 72-87, abr./jun. 1988.

VILLELA, Álvaro da Costa Machado. O direito internacional privado no Código Civil Brasileiro. Coimbra: Imprensa da Universidade de Coimbra, 1921. 